\title{
Comparative Study of Project Based Learning Over Lecture in Acquisition of 3D Anatomical Knowledge in Medical Students
}

\author{
Sabu A.N. ${ }^{1}$
}

${ }^{1}$ Department of ENT, Government Medical College, Ernakulam, Kerala, India.

\section{ABSTRACT}

\section{BACKGROUND}

Many students attending ENT clinical postings were found to have difficulty in conceptualising the 3-dimensional (3 D) anatomy of the ear, nose and throat. Students in project-based learning (PBL) classrooms obtained higher scores than students in traditional classrooms. PBL using clay model and modelling compound have been successfully used to improve the $3 \mathrm{D}$ anatomical understanding in medical students. The purpose of this study was to compare the effectiveness of PBL over lecture in the acquisition of $3 \mathrm{D}$ anatomical knowledge among third-year undergraduate medical students and also to understand the student perception towards PBL.

\section{METHODS}

This quasi-experimental study was done at GMC, Ernakulam among 84 third-year undergraduate medical (MBBS) students who had given consent for the study. They were divided into 3 batches according to roll numbers (28 students in each). Two topics in ENT anatomy were selected. 14 students of one batch attended lecture class, while the remaining 14 attended PBL class. This was repeated for the remaining two batches. In the next week, a cross-over was given for the second topic. Pre-test and post-test for both topics were administered to all the students before and after the sessions. Feedback regarding the student perceptions about PBL was obtained.

\section{RESULTS}

There was a statistically significant difference between the mean of pre-test and post-test scores ( $p$ values of 0.001 ) in both lecture and PBL groups in both topics. The mean of pre-test scores of the lecture group and PBL in both topics did not show any significant difference. There was a statistically significant difference between the mean of post-test scores in the case of nose topic ( $p$ value 0.004 ). 88\% of students had a favourable view of PBL as a teaching methodology. There was no statistically significant difference across the genders in their perception of the PBL as a teaching-learning method. ( $\mathrm{p}$ value 0.314 )

\section{CONCLUSIONS}

The study shows that both PBL and lecture brought about significant change in the knowledge level of the student. The students had a favourable opinion regarding PBL as a teaching method. However, PBL was not found to be more beneficial than conventional lecture in the acquisition of knowledge.

\section{KEY WORDS}

Anatomy Education; Medical Education; Project-Based Learning; Didactic Lecture.
Corresponding Author:

Dr. Sabu A.N.

Department of ENT,

Government Medical College,

Ernakulam, Kerala, India.

E-mail:drsabu.an@gmail.com

DOI: $10.14260 /$ jemds/2022/43

How to Cite This Article:

Sabu AN. Comparative study of project based learning over lecture in acquisition of 3D anatomical knowledge in medical students. I Evolution Med Dent Sci 2022;11(01):222-227, $10.14260 / \mathrm{jemds} / 2022 / 43$

Submission 12-12-2021,

Peer Review 25-01-2022,

Acceptance 29-01-2022,

Published 31-01-2022.

Copyright (c) 2022 Sabu A.N. et al. This is an open access article distributed under Creative Commons Attribution License [Attribution 4.0 International (CC BY 4.0)] 


\section{BACKGROUND}

Many students attending ENT clinical postings are found to have difficulty in conceptualising the 3-dimensional (3 D) anatomy of the ear, nose, and throat. This is essential in understanding the pathophysiology and spread of diseases and the principles behind the various surgical approaches and techniques used for the treatment of the disease conditions.

Knowledge of the $3 \mathrm{D}$ anatomy of the nose has become all the more relevant after the Covid-19 pandemic, with the huge number of nasal and nasopharyngeal swabs performed all over the world. Lack of knowledge of nasal anatomy has resulted in complications like cerebrospinal fluid (CSF) leak and meningitis. ${ }^{1,2}$ Thorough knowledge of the threedimensional anatomy of the nose is essential for medical students and interns to minimise unnecessary injuries while performing outpatient procedures. ${ }^{3}$ The middle and inner ear are clinically inaccessible when compared to the pinna and external ear canal. ${ }^{4}$ This has resulted in the development of a plethora of 3D technologies for improving the anatomical understanding of these structures.5,6 However, most of these technologies are expensive and not widely accessible in the developing world.

Modelling compounds and clay are cheap and easily available and provide a kinaesthetic, three-dimensional, constructive, and sensory approach to learning human anatomy. ${ }^{7}$

Lecture-based learning (LBL) still forms the core of medical education in most medical colleges ever since it was implemented by the American Medical College Association and the American Academy of Medicine in $1894 .{ }^{8}$ Traditionally, anatomy is taught mainly in these didactic lecture classes. Though lectures remain a useful cost-effective method of disseminating knowledge efficiently, the threedimensional nature of anatomical structures is poorly conveyed by them. They also do not encourage collaboration or develop problem-solving skills. ${ }^{9}$

Active learning strategies engage students in the habit of contemplative discussion and critical analysis of situations and help the learners to take full advantage of the impact of the material.10 Project-based learning (PBL) "may be defined as using authentic, real-world projects, based on a highly motivating and engaging question, task, or problem to teach students academic content in the context of students working cooperatively to solve the problem and complete the project". ${ }^{11}$ Project-based learning is most favoured in the field of engineering, industrial sciences, and architecture. ${ }^{12,13}$

Project-based learning is often confused with problembased learning. Problem-based learning was introduced at the McMaster University Medical School, Canada by Howard Barrows and Robyn Tamblyn in the 1960s. ${ }^{14}$ It is an inquiry based approach to learning that is student centered and provides the means for gaining problem-solving and life-long learning skills. $15,16,17$

There is only a very fine distinction between projectbased and problem-based learning. The difference between them is that the students in problem-based learning are primarily focused on the process of learning, while projectbased learning needs to culminate in an end product. The essence of project-based learning is that a question or problem serves to organize and drive activities, and these activities culminate in a final product that addresses the driving question. ${ }^{18}$

Students in project-based learning classrooms get higher scores than students in traditional classrooms and have increased long-term retention of skills and concepts. ${ }^{19,20} \mathrm{PBL}$ using clay model and modelling compound has been successfully used to improve the $3 \mathrm{D}$ anatomical understanding in medical students. ${ }^{21}$ There is a dearth of literature on project-based teaching methods in medical education. Very few studies have been conducted using modelling compound in the teaching of applied anatomy in ENT and as a project-based teaching-learning method in the field of medical education.

The present study was conducted with a hypothesis that project-based learning using modelling compounds is better than lecture in helping the medical students develop a $3 \mathrm{D}$ anatomical knowledge of the middle ear and the lateral wall of the nose. The purpose of this study was to compare the effectiveness of PBL over lecture in the acquisition of 3-D anatomical knowledge of the middle ear and lateral wall of the nose in third-year MBBS students and also to understand the student perception towards PBL.

\section{METHODS}

This quasi-experimental study was done at Government Medical College (GMC), Ernakulam from November 2017 to December 2017 among 84 third-year undergraduate medical (MBBS) students who had given consent for the study. They were divided into 3 batches according to roll numbers (28 students in each). 2 topics in ENT anatomy were selected. 14 students of one batch attended lecture class, while the remaining 14 attended PBL class. This was repeated for the remaining 2 batches. For the second topic, a cross-over was given. Pre-test and post-tests for both topics were administered to all the students. Feedback regarding the student perceptions about PBL was obtained.

Ethical approval was granted by the Institutional Ethics Committee, GMC Ernakulam. (IEC/40/17 dt 14/11/2017). Informed written consent was also obtained from all the students who participated in the study. From the class of 91 MBBS students, 7 were absent and hence excluded. The remaining 84 students were included in the study.

To avoid overcrowding of the students and for smooth conduct of the study, they were divided according to their roll numbers into 3 batches (28 students each).

Two topics-anatomy of the middle ear and lateral wall of the nose were chosen for the study.

Two sets of separate questionnaires for ear and nose were used for the pre and post-tests. Each set comprised of peer-validated multiple-choice questions (MCQs). A five-point Likert scale questionnaire, validated by conducting a pilot study in a smaller group comprising of senior students was used to obtain feedback at the end of the PBL sessions.

Initially, a pre-test was given to the first batch of 28 students. They were then divided into two groups of equal number of students (14).

In the first week, the anatomy of the middle ear was chosen as the topic. The first half of the batch (14 students)

was given a lecture class on the anatomy of the middle ear (Lecture group-Ear), while the second half of the batch (14 
students) was given a project (PBL group-Ear) for preparing a model of the anatomy of the middle ear using modelling compound -Play-Doh and cardboard. To avoid interaction and sharing of learning materials, both groups were assigned separate classrooms for the learning activities. A facilitator remained in the PBL classroom to give appropriate instructions. A post-test was conducted immediately at the end of the session in both the lecture and PBL groups. The same process was repeated for the remaining two batches of students.

In the second week, the lateral wall of the nose was chosen as the topic. A cross-over was given this time so that the students were exposed to both teaching modalities.

After the pre-test, the group which was given a lecture class on the middle ear was now given a project (PBL) for preparing an anatomical model of the lateral wall of the nose (PBL group-Nose). The group which was given a project (PBL group-Ear) for preparing the middle ear anatomy model was now given lecture class on the lateral wall of the nose (Lecture group-Nose). A post-test was conducted immediately at the end of the session in both groups.

\section{Statistical Analysis}

The scores of the multiple-choice questions obtained were entered in a Microsoft Excel spreadsheet. Feedback was obtained at the end of the session and the perceptions of the students about the teaching methods were recorded on a 5point Likert scale. The feedback questionnaire had been validated by a pilot study conducted on a smaller group comprising of ten senior students and the necessary corrections were made.

Data was also obtained on the demographics of the participants and their previous exposure to the subject matter.

Statistical analysis was made using SPSS software (version 21.0). The Mean scores of the groups were analysed using paired and unpaired t-tests. Paired t-test was done to compare the difference in the mean of the pre and post-test scores gained by the students in the lecture and PBL sessions. Unpaired t-test was done to compare the mean of the pre and post-test scores obtained by the two methodologies. The relation of gender with the overall perception of PBL with modelling compound was tested using the chi-square test.

\section{RESULTS}

\begin{tabular}{|ccccccc|}
\hline Topic & Group & Test & $\begin{array}{c}\text { No. of } \\
\text { Students }\end{array}$ & Mean & $\begin{array}{c}\text { Std. } \\
\text { Deviation }\end{array}$ & p Value \\
& Lecture & Pre-test & 42 & 5.595 & 2.142 & 0.001 \\
Ear & group & Post-test & 42 & 8.095 & 1.322 & \\
& Project & Pre-test & 42 & 5.857 & 2.322 & 0.001 \\
& group & Post-test & 42 & 8.071 & 1.472 & \\
& Lecture & Pre-test & 42 & 4.429 & 1.417 & 0.001 \\
Nose & group & Post-test & 42 & 6.643 & 1.723 & \\
& Project & Pre-test & 42 & 4.5 & 1.612 & 0.001 \\
\hline Table 1. Comparison of Mean of Pre and Post-test Scores -Lecture and \\
& group & Post-test & 42 & 5.595 & 1.483 & \\
\hline
\end{tabular}

After the intervention, there was a definite improvement in the mean pre-test scores, in both PBL and lecture groups in both topics. As depicted in Table: 1, this difference was statistically significant with a p value of 0.001 .

As seen in Table: 2, there was no statistically significant difference in the mean pre-test scores of both the lecture and PBL groups in both ear and nose topics. ( $p$ value 0.59 and 0.83 respectively)

\begin{tabular}{|ccccccc|}
\hline Test & Group & Test & N & Mean & $\begin{array}{c}\text { Std. } \\
\text { Deviation }\end{array}$ & p Value \\
& Lecture group-Ear & Pre-test 1 & 42 & 5.595 & 2.142 & 0.59 \\
Pre-test & PBL group-Ear & Pre-test 1 & 42 & 5.857 & 2.322 & \\
\cline { 2 - 5 } & Lecture group-Nose & Pre-test 2 & 42 & 4.429 & 1.417 & 0.83 \\
\hline & PBL group-Nose & Pre-test 2 & 42 & 4.500 & 1.612 & \\
\hline \multicolumn{5}{|c|}{ Table 2. Comparison of Mean of Pre-test Scores -Lecture and PBL } \\
(Ear and Nose)
\end{tabular}

As shown in Table: 3, it was found that the mean post-test score for the lecture group was higher when compared to the PBL group in the case of the nose topic. This difference was statistically significant with a $p$ value of 0.004 .

In the ear topic, there was no significant difference between the mean post test scores of the lecture group and PBL group ( $p$ value 0.938 )

\begin{tabular}{|ccccccc|}
\hline Test & Group & Test & N & Mean Std. Deviation p Value \\
& Lecture group-Ear & Post- test 1 & 42 & 8.095 & 1.323 & 0.938 \\
$\begin{array}{c}\text { Post- } \\
\text { test }\end{array}$ & PBL group-Ear & Post-test 1 & 42 & 8.071 & 1.472 & \\
& Lecture group-Nose & Post-test 2 & 42 & 6.643 & 1.723 & 0.004 \\
& PBL group-Nose & Post-test 2 & 42 & 5.595 & 1.483 & \\
\hline \multicolumn{2}{|c|}{ Table 3. Comparison of Mean of Post-test Scores -Lecture and PBL } \\
\multicolumn{5}{c}{ (Ear and Nose) } \\
\hline
\end{tabular}

Table: 4 and Fig: 1 presents the student perception regarding PBL activity. The majority of the students (88\%) had a favourable view of PBL as a teaching method. Most of the students opined that PBL helped in improving attention (94\%), arousing interest in the subject (89.3\%), and understanding the anatomical concepts better $(83.4 \%)$. Unfavourable opinions among the students regarding the PBL ranged from $6-16.7 \%$.

\begin{tabular}{|cccccccc|}
\hline $\begin{array}{c}\text { Perception- } \\
\text { variables }\end{array}$ & $\begin{array}{c}\text { Total } \\
\text { No. of } \\
\text { Students }\end{array}$ & $\begin{array}{c}\text { Very } \\
\text { Good }\end{array}$ & Good & Fair & Poor & $\begin{array}{c}\text { Very } \\
\text { Poor }\end{array}$ \\
$\begin{array}{c}\text { Arouses interest } \\
\text { in the subject } \\
\text { Improves }\end{array}$ & 84 & $49(58.3)$ & $26(31)$ & $8(9.5)$ & $1(1.2)$ & $0(0)$ \\
$\begin{array}{c}\text { attention } \\
\text { Understanding } \\
\text { anatomical } \\
\text { concepts better } \\
\text { Overall }\end{array}$ & 84 & $49(58.3)$ & $30(35.7)$ & $4(4.8)$ & $1(1.2)$ & $0(0)$ \\
$\begin{array}{c}\text { assessment of } \\
\text { the teaching } \\
\text { method }\end{array}$ & 84 & $45(53.6)$ & $25(29.8)$ & $9(10.7)$ & $5(6)$ & $0(0)$ \\
\hline \multicolumn{7}{c|}{ Table 4. Distribution of Perception Regarding PBL } & \\
\hline
\end{tabular}

27 male and 57 female students participated in the study. 92.6\% (25) male students perceived PBL as a good teachinglearning method, while only $86 \%$ (42) female students perceived PBL as good. Even though there was an absolute difference in the perception of PBL with gender, the chisquare test revealed that this difference was not statistically significant ( $p$ value 0.314.) as seen in Table: 5 . 


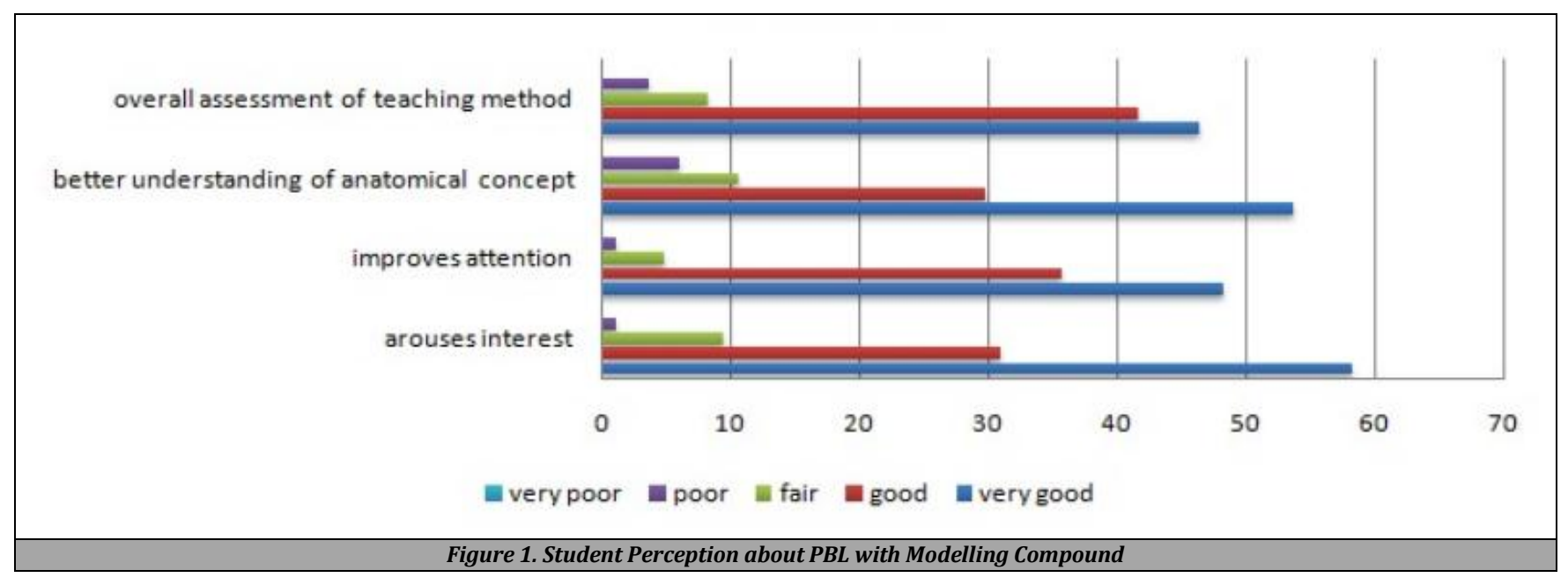

\begin{tabular}{|cccc|}
\hline Gender & Poor N (\%) & Good N (\%) & Total N (\%) \\
Male & $2(7.4)$ & $25(92.6)$ & $27(100)$ \\
Female & $8(14)$ & $49(86)$ & $57(100)$ \\
Total & $\mathbf{1 0}(\mathbf{1 1 . 9 )}$ & $\mathbf{7 4}(\mathbf{8 8 . 1 )}$ & $\mathbf{8 4}(\mathbf{1 0 0 )})$ \\
$\times 2=0.767$ d.f $1 p$ 0.314 & \multicolumn{3}{|c|}{ Table 5. Relation of Gender - Overall Perception of PBL with } \\
& Modelling Compound \\
\hline
\end{tabular}

\section{DISCUSSION}

Project-based learning and problem-based learning is similar in many aspects. Though problem -based learning is well established in medical education, there is a paucity of projectbased studies in anatomy and medical education.

In a study conducted to find out the effectiveness of PBL when compared to traditional teaching in gross anatomy, among first-year medical students in Iran, it was found that the PBL method resulted in better examination scores compared to the traditional teaching methods. ${ }^{22}$ Several studies have shown that, when manipulative materials like clay were used, the students showed gains in their knowledge immediately after the activities. ${ }^{23,24}$

In the present study, it was seen that both lecture and PBL resulted in significant knowledge gain after intervention in both the anatomy topics selected. This was similar to the results of a study by Shruthi et al. who compared tutorials with PBL in the instruction of anatomy topics, among firstyear undergraduate medical students; wherein it was observed that there was a statistically significant difference in the mean scores between pre and post-test with both tutorials and PBLs. This indicated that knowledge attained in both the tutorial and PBL sessions was of a greater level. ${ }^{25}$

In this study, the comparison of pre-test scores of both lecture and PBL groups in both topics did not show any significant difference. This shows that all groups were having comparable knowledge levels before intervention.

After the intervention, both PBL and lecture could bring about statistically significant change in the baseline knowledge level of the students in both the ear and nose topics.

Comparison of the post-test scores in this study revealed that both PBL and lecture were found to be equally effective in the instruction of ear anatomy. But it was noted that the lecture was more effective than PBL in the instruction of anatomy of the lateral wall of the nose.
The probable reasons for this could be the novelty of the teaching method to both students, the unfamiliarity of the students with the modelling compound, as well as the difficulty of the topic selected.

Thus, it was seen that PBL was not found to be more beneficial than conventional lectures in the acquisition of knowledge. This is in contrast to the findings of studies comparing lectures with PBL. ${ }^{24}$

In a systematic literature review on studies comparing PBL with the conventional mode of teaching, Nandi P L et al. found that there was no convincing evidence of enhanced learning using PBL although, both these curricula encouraged diverse ways of learning. ${ }^{26}$

This study shows that the students widely appreciated the PBL teaching method and consider it to arouse interest in the subject, improve attention and help in understanding anatomical concepts better. A similar observation was made in a study describing the implementation of project-based learning among first-year veterinary anatomy students. The majority $(80 \%)$ favoured active learning compared to traditional classes and were of the opinion that it helped them understand the theoretical content of the subject better. ${ }^{13}$ In the study by Khaki et al. the students were found to be happier with the PBL method and believed that it improved their perception regarding their anatomical knowledge and their problem-solving skills. ${ }^{22}$ The studies conducted in the physiology, pharmacology departments of various medical colleges also elicited a comparable and favourable response from the medical students. ${ }^{27,28}$ In a literature review of over nineteen years, Nandi et al. observed that not only the students but also the teachers enjoyed the PBL curriculum. ${ }^{26}$

In this study, there was no significant difference between male and female students in their perception of the PBL as a teaching method. This was in agreement with the findings of the study by Singaram et al. in which there was no significant variation in the student perception with gender, age, first language, prior educational training, or the type of schools they have previously attended.29 However, in a study conducted among medical students in UAE, there was a significant difference among the genders, in their perception of project-based learning, with a higher proportion of females preferring projects over males. The authors posit that sociocultural reasons could be responsible for this difference among genders. ${ }^{30}$ 
One of the limitations of this study was that the study duration was for a short period. The post-tests taken immediately after both lecture and project showed improvement in scores. Follow-up tests must be conducted in both groups for assessing long-term retention of knowledge, to give a definite opinion on the effectiveness of the project. Most of the students were using modelling compounds for the first time and were not familiar with PBL sessions.

\section{CONCLUSIONS}

In conclusion, both project-based teaching and lecture brought about significant change in the knowledge level of the student. While the study did not show that PBL was more beneficial than conventional lecture in the acquisition of knowledge, the PBL approach was widely favoured by the students as a Teaching-Learning Method (TLM).

More PBL methods using art-based methods and manipulatives should be incorporated along with small group discussions and lectures in teaching complex $3 \mathrm{D}$ anatomy, especially in ENT. A blend of both traditional teaching and PBL activities will offer the most effective training to undergraduate students.

Data sharing statement provided by the authors is available with the full text of this article at jemds.com.

Financial or other competing interests: None.

Disclosure forms provided by the authors are available with the full text of this article at jemds.com.

The author would like to thank Dr. Manjula. S, HOD Community Medicine, and Dr. Alwin Antony, Assistant Professor, Community Medicine, GMC Ernakulam for the help in statistical analysis, and also Dr. Sajith Kumar, R. Professor and Head Infectious Diseases, Govt. Medical College, Kottayam for guidance. The author also thanks students of GMC Ernakulam for participating in the study. This study was conducted as part of Advance Course in Medical Education (ACME-5) conducted by MCI Nodal Centre for Faculty Development, GMC, Kottayam in 2017.

\section{REFERENCES}

[1] Sullivan CB, Schwalje AT, Jensen M, et al. Cerebrospinal fluid leak after nasal swab testing for coronavirus disease 2019. JAMA Otolaryngol Head Neck Surg 2020;146(12):1179-81.

[2] Mistry SG, Walker W, Earnshaw J, et al. COVID-19 swabrelated skull base injury. Med J Aust 2021;214(10):457459.e1.

[3] Bright RR, Varghese L, Kurien R. Construct and validation of a three-dimensional physical model for training in transnasal office procedures. Indian Journal of Otolaryngology and Head \& Neck Surgery 2021:1-8.

[4] Mukherjee P, Cheng K, Wallace G, et al. 20 year review of three-dimensional tools in otology: challenges of translation and innovation. Otol Neurotol 2020;41(5):589-95.

[5] Glueckert R, Johnson LC, Schmidbauer D, et al. Visualization of the membranous labyrinth and nerve fiber pathways in human and animal inner ears using MicroCT imaging. Front Neurosci 2018;12:501.
[6] Mukherjee P, Cheng K, Curthoys I. Three-dimensional study of vestibular anatomy as it relates to the stapes footplate and its clinical implications: an augmented reality development. J Laryngol Otol 2019;133(3):18791.

[7] DeHoff ME, Clark KL, Meganathan K. Learning outcomes and student-perceived value of clay modeling and cat dissection in undergraduate human anatomy and physiology. Adv Physiol Educ 2011;35(1):68-75.

[8] Barr DA. Revolution or evolution? Putting the Flexner Report in context. Med Educ 2011;45(1):17-22.

[9] Brenton H, Hernandez J, Bello F, et al. Using multimedia and Web3D to enhance anatomy teaching. Computers \& Education 2007;49(1):32-53.

[10] Nelson LP, Crow ML. Do Active-learning strategies improve students' critical thinking? High Educ Stud 2014;4(2):77-90.

[11] Barell J. Problem-based learning: the foundation for 21st Century skills. In: Bellanca J, Brandt R, eds. 21st Century skills: rethinking how students learn. Bloomington: Solution Tree Press 2010:175-200.

[12] Hong JC, Lin CL, Huang HC. The comparison of problembased learning (PmBL) model and project-based learning (PtBL) model. InInternational Conference on Engineering Education (ICEE) 2007.

[13] Borroni C, Pimentel-Ávila A, Stoore C, et al. A unique approach to project-based learning (PjBL) in a veterinary anatomy course. Med Sci Educ 2021;31(2):511-7.

[14] Barrows H, Tamblyn R. An evaluation of problem-based learning in small groups utilizing a stimulated patient. J Med Educ 1976;51:52-4.

[15] Becker KH, Maunsaiyat S. A comparison of students' achievement and attitudes between constructivist and traditional classroom environments in Thailand vocational electronics programs. Journal of Vocational Education Research 2004;29(2):133-53.

[16] Blumberg P. Evaluating the evidence that problem-based learners are self directed learners: a review of the literature. In: Evensen DH, Hmelo EE, eds. Problembased learning: A research perspective on learning interactions. Mahwah, NJ: Erlbaum 2000;199-226.

[17] Chen SK, Chang HF, Chiang CP. Group learning factors in a problem based course in oral radiology. Dentomaxillofac Radiol 2001;30(2):84-7.

[18] Blumenfeld PC, Soloway E, Marx RW, et al. Motivating project-based learning: sustaining the doing, supporting the learning. Educ Psychol 1991;26(3-4):369-98.

[19] Geier R, Blumenfeld PC, Marx RW, et al. Standardized test outcomes for students engaged in inquiry-based science curricula in the context of urban reform. Journal of Research in Science Teaching 2008;45(8):922-39.

[20] Karaçalli S, Korur F. The effects of project-based learning on students academic achievement, attitude, and retention of knowledge: the subject of electricity in our lives. School Science and Mathematics 2014;114(5):22435.

[21] Oh CS, Kim JY, Choe YH. Learning of cross-sectional anatomy using clay models. Anat Sci Educ 2009;2(4):156-9. 
[22] Khaki AA, Tubbs RS, Zarrintan S, et al. The first year medical students perception of and satisfaction from problem-based learning compared to traditional teaching in gross anatomy: introducing problem-based anatomy into a traditional curriculum in Iran. Int J Health Sci (Qassim) 2007;1(1):113-8.

[23] Krontiris-Litowitz J. Using manipulatives to improve learning in the undergraduate neurophysiology curriculum. Adv Physiol Educ 2003;27(1-4):109-19.

[24] Herur A, Kolagi S, Chinagudi S, et al. Active learning by play dough modeling in the medical profession. Adv Physiol Educ 2011;35(2):241-3.

[25] Shruthy KM, Raizada A, Chanemougavally J, et al. A comparative study of the effectiveness of problem-based learning versus tutorials in first-year MBBS students. MedPulse International J Anatomy 2021;19(2):20-4.

[26] Nandi PL, Chan JN, Chan CP, et al. Undergraduate medical education: comparison of problem-based learning and conventional teaching. Hong Kong Med J 2000;6(3):3016.

[27] Nerurkar A, Dhanani J. Effectiveness of Project based learning in teaching microbiology to undergraduate medical students. IOSR Journal of Research \& Method in Education (IOSR-JRME) 2016:2320-7388.

[28] Deb T, Singh R, Mukhopadhyay K. Students perception and practice in learning basic pharmacology through a 'Project Based Learning' programme. Indian J Res Rep Med Sci 2013;3(2):28-31.

[29] Singaram VS, Dolmans DHJM, Lachman N, et al. Perceptions of problem-based learning (PBL) group effectiveness in a socially-culturally diverse medical student population. Educ Health (Abingdon) 2008;21(2):116.

[30] Kershaw G, Grivna M, Elbarazi I, et al. Integrating public health and health promotion practice in the medical curriculum: a self-directed team-based project approach. Front Public Health 2017;5:193. 